\title{
Lysophosphatidic acid induces the migration and invasion of SGC-7901 gastric cancer cells through the LPA2 and Notch signaling pathways
}

\author{
ZHIHENG REN $^{1 *}$, CHENLI ZHANG $^{1 *}$, LINNA MA $^{1}$, XIAO ZHANG $^{1}$, SHUXIA SHI $^{2}$, DENG TANG $^{1}$, \\ JINYU XU ${ }^{1}$, YAN HU ${ }^{1}$, BINSHENG WANG ${ }^{3}$, FANGFANG ZHANG ${ }^{1}$, XU ZHANG $^{1}$ and HAIXUE ZHENG ${ }^{4}$ \\ ${ }^{1}$ Department of Pathology, School of Basic Medicine, Lanzhou University; ${ }^{2}$ Clinical Teaching Department of \\ Lanzhou Modern Vocational College; ${ }^{3}$ Department of Third General Surgery, The First Hospital of Lanzhou University; \\ ${ }^{4}$ National Foot and Mouth Diseases Reference Laboratory, Lanzhou Veterinary Research Institute, \\ Chinese Academy of Agricultural Sciences, Lanzhou, Gansu 730000, P.R. China
}

Received August 25, 2018; Accepted April 16, 2019

DOI: $10.3892 / \mathrm{ijmm} .2019 .4186$

\begin{abstract}
Lysophosphatidic acid (LPA), a simple water-soluble glycerophospholipid with growth factor-like activity, regulates certain behaviors of multiple cancer types by binding to its receptor, LPA receptor 2 (LPA2). Notch1 is a key mediator in multiple human cancer cell types. The association between LPA2 and Notch1 in gastric cancer cells is not well known. The present study aimed to investigate the function of LPA2 and Notch1 in controlling the migration and invasion activities of SGC-7901 gastric cancer cells following stimulation with LPA. It was revealed that LPA may stimulate the expression of Notch1 and Hes family bHLH transcription factor 1, and the phosphorylation of protein kinase B which belongs to the Notch pathway. Furthermore, by performing transwell migration and invasion assays, immunofluorescent staining, analyzing the expression of markers for the epithelial-mesenchymal transition (EMT) and downregulating LPA2 and Notch1 expression, it was verified that LPA2 and Notch1 mediated the metastasis, invasion, EMT and rebuilding of the cytoskeleton of SGC-7901 cells upon LPA treatment. An immunoprecipitation assay revealed that LPA2 interacted with Notch1 in SGC-7901
\end{abstract}

Correspondence to: Professor Xu Zhang, Department of Pathology, School of Basic Medicine, Lanzhou University, 222 Tianshui Road, Lanzhou, Gansu 730000, P.R. China

E-mail: zhangxu64@163.com

Professor Haixue Zheng, National Foot and Mouth Diseases Reference Laboratory, Lanzhou Veterinary Research Institute, Chinese Academy of Agricultural Sciences, 1 Yanchang Road, Lanzhou, Gansu 730000, P.R. China

E-mail: haixuezheng@163.com

${ }^{*}$ Contributed equally

Key words: lysophosphatidic acid, lysophosphatidic acid receptor 2, Notch1, migration, invasion, epithelial-to-mesenchymal transition cells. The present study may provide novel ideas and an experimental basis for identifying the factors that affect the functions of SGC-7901 cells.

\section{Introduction}

Gastric cancer is one of the most common malignant gastrointestinal tumor types globally (1). Numerous novel cases of gastric cancer occur in developing countries, of which $~ 50 \%$ of patients live in Eastern Asia and are mainly concentrated in China (2). There is no effective treatment for the patients in those regions, which seriously affects the survival of the patients.

Lysophosphatidic acid (LPA) is produced by the autotoxin hydrolysis of lysophosphatidylcholine (3). As the simplest form of a glycerophospholipid, LPA is associated with malignant behaviors including tumor invasion and metastasis, which may inhibit tumor cell apoptosis and promote its proliferation in situ (4). LPA receptors are divided into six subtypes, including LPA1-LPA6. LPA1-LPA3 are members of the endothelial cell differentiation gene (EDG) family, while LPA4-LPA6 belong to the purine receptor family (5). When a specific LPA receptor binds to LPA, it may cause a corresponding biological effect (6). In the research of malignant tumor types, LPA2 (also known as EDG4) has been widely studied and is highly expressed in a number of different tumor tissue types, including breast cancer, liver cancer, gastric cancer and colorectal cancer (7-9). LPA2 is also involved in biological behaviors, including proliferation, anti-apoptosis, drug resistance, metastasis and the invasion of numerous cancer cells, resulting in poor clinic outcomes (10-13). Furthermore, LPA upregulates the expression of matrix metalloprotein- 9 through activating the nuclear factor- $\kappa$ B pathway in a LPA2 dependent manner (14).

The Notch signaling pathway is involved in cell differentiation, proliferation, apoptosis and adhesion (15). It also serves a key function in maintaining the function of normal cells and tissues. Abnormal activation of the Notch signaling pathway is associated with the pathogenesis of a number of different 
malignancies (16). There are four single-stranded transmembrane receptors (Notch1-4) in the Notch signaling pathway. These receptors may be cleaved by $\gamma$-secretase following binding to the ligands Jagged1, Jagged2, Delta1, Delta3 and Delta4 (17). Following binding, the Notch intracellular domain (NICD) is released and enters the nucleus, where it stimulates the transcription of downstream target genes, including Hes Family BHLH Transcription Factor 1 (Hes-1), protein kinase B (Akt) and Cyclin D1, amongst others (18). Notch1 is abnormally expressed in a variety of tumor cells and is associated with the poor biological behavior of malignant tumor types, and the invasion and metastasis of non-small cell lung cancer (NSCLC) cells. NSCLC cells are regulated by Notch1, and the downregulation of the Notch1 gene in SGC-7901 gastric cancer cells inhibits their proliferation and invasion $(19,20)$. Notch1 is also highly expressed in gastric cancer tissues and is associated with a poor prognosis (21).

Invasion and migration are the preconditions for the metastasis of malignant tumor types (22). Previous studies focus on the factors that regulate invasion and metastasis in the early stage of cancer development, with the purpose of providing a reliable foundation for early diagnosis and treatment (23-25). The epithelial-mesenchymal transition (EMT) program of tumor cells is closely associated with invasion and migration $(26,27)$. Cells lose polarity during EMT, undergo remodification of the cytoskeleton, alter their original morphology and transform into cells with the capacity to relocate during EMT (28). During this process, the expression of the epithelial marker E-Cadherin is decreased, while the expression of the mesenchymal markers vimentin, $\mathrm{N}$-cadherin and Snail Family Transcriptional Repressor 1 are increased $(29,30)$.

A previous study has revealed that LPA2 is involved in the apoptosis, invasion and migration of SGC-7901 cells, and that the downregulation of LPA2 reduces the expression of Notch1 in those cells (31). However, the association between LPA2 and Notch1 remains unclear. The present study aimed to investigate whether LPA2 and Notch1 were able to coregulate the invasion and migration of SGC-7901 gastric cancer cells, to providing novel insight for the study of molecular pathological diagnosis of gastric cancer cells.

\section{Materials and methods}

Cell culture and treatment. GES-1 and SGC-7901 cell lines were obtained from the Laboratory of Pathology, School of Basic Medicine, Lanzhou University (Lanzhou, China) (32). Cells were maintained in RPMI-1640 medium (Hyclone; GE Healthcare Life Sciences, Logan, UT, USA) and supplemented with $1 \%$ penicillin/streptomycin (Sigma-Aldrich; Merck KGaA, Darmstadt, Germany), supplemented with 10\% fetal bovine serum (FBS; Biological Industries, Kibbutz Beit Haemek, Israel). All cells were incubated at $37^{\circ} \mathrm{C}$ in $5 \% \mathrm{CO}_{2}$ and saturated humidity.

LPA treatment. GES-1 and SGC-7901 cells were seeded in 6 -well plates at a density of $2 \times 10^{5}$ cells/well, and the monolayer cells were treated with or without different doses of Oleoy-L-Alpha-Lysobisphosphatidic acid (Sigma-Aldrich; Merck KGaA) dissolved in dimethyl sulfoxide. Cells were then collected after incubation with LPA for $24 \mathrm{~h}$, and analyzed using western blotting.

$R N A$ isolation and reverse transcription-quantitative polymerase chain reaction ( $R T-q P C R)$. Total RNA was extracted from GES-1 and SGC-7901 cells using TRIzol ${ }^{\circledR}$ reagent (Invitrogen; Thermo Fisher Scientific, Inc., Waltham, MA, USA) according to the protocol, and the steps of extraction were performed on ice. RT-qPCR was performed using Moloney murine leukemia virus reverse transcriptase (Promega Corporation, Madison, WI, USA) and random hexamer primers (Takara Bio, Inc., Otsu, Japan). The conditons for reverse transcription were set as: $25^{\circ} \mathrm{C}$ for $10 \mathrm{~min} ; 37^{\circ} \mathrm{C}$ for $60 \mathrm{~min}$; and $70^{\circ} \mathrm{C}$ for $15 \mathrm{~min}$. The resulting cDNAs were used for qPCR. The transcription levels of mRNAs were quantified by qPCR using SYBR Premix Ex Taq reagents (Takara Bio, Inc.) in the Mx3005P qPCR System (Agilent Technologies, Inc., Santa Clara, CA, USA). GAPDH was used as an internal control. The qPCR primers are listed in Table I. The theromocyling conditions were set as: $95^{\circ} \mathrm{C}$ for $2 \mathrm{~min}$ (hold stage); $95^{\circ} \mathrm{C}$ for $10 \mathrm{sec}, 60^{\circ} \mathrm{C}$ for $34 \mathrm{sec}\left(40\right.$ cycles, PCR stage); $95^{\circ} \mathrm{C}$ for $15 \mathrm{sec}$, $60^{\circ} \mathrm{C}$ for $1 \mathrm{~min}, 95^{\circ} \mathrm{C}$ for $1 \mathrm{sec}$ (melt curve stage). The relative fold changes of mRNA were calculated using the comparative cycle threshold $\left(2^{-\Delta \Delta C q}\right)$ method (33). All experiments were repeated three times with similar results. The data presented represent the results of one of the triplicate experiments.

Western blotting and co-immunoprecipitation (co-IP) assay. GES-1 and SGC-7901 cells were harvested and lysed using protein loading buffer (Beijing Solarbio Science \& Technology Co., Ltd., Beijing, China) containing 1\% PMSF protease inhibitors. Firstly, the cells were lysed for $10 \mathrm{~min}$ on ice, and then transferred to centrifuge tubes and heated for $10 \mathrm{~min}$ in boiling water at $100^{\circ} \mathrm{C}$. The total protein concentration was measured using a BCA Protein assay kit (Pierce; Thermo Fisher Scientific, Inc.) according to the manufacturer's protocol. In total, $300 \mu \mathrm{g}$ protein was loaded per lane and separated on $10 \%$ SDS-PAGE for $1 \mathrm{~h}$ at room temperature. The resolved proteins were transferred to polyvinylidene difluoride membranes. After $2 \mathrm{~h}$ transfer in cold transfer buffer, the membranes were blocked for $2 \mathrm{~h}$ at room temperature with 5\% skimmed milk and incubated with primary antibodies [LPA2 (additionally termed EDG-4), Notch1, Hes-1, Akt, p-Akt, E-Cadherin, vimentin, $\mathrm{F}$-actin, $\beta$-actin] overnight at $4^{\circ} \mathrm{C}$. Membranes were then incubated with secondary horseradish peroxidase (HRP)-labeled antibodies (goat anti-rabbit IgG or goat anti-mouse $\mathrm{IgG}$ ) for $2 \mathrm{~h}$ at room temperature and visualized using Electro-Chemi-Luminescence detection reagent (Thermo Fisher Scientific, Inc.) and Image Lab ${ }^{\mathrm{TM}}$ software 4.1 (Bio-Rad Laboratories, Inc., Hercules, CA, USA) was used to select the optimum exposure blot. The changes in the abundance of proteins were determined by densitometric analysis using ImageJ Software 1.4.3.67 (National Institutes of Health, Bethesda, MD, USA) and normalized to $\beta$-actin, as previously described (34).

For co-IP assays, SGC-7901 cells were cultured in $6 \mathrm{~cm}$ dishes, and the monolayer cells were treated with or without $15 \mu \mathrm{M}$ LPA. Cells were lysed at $4^{\circ} \mathrm{C}$ using RIPA Lysis buffer (Beijing Solarbio Science \& Technology Co., Ltd.) for $20 \mathrm{~min}$, and the lysates were centrifuged at $12,000 \mathrm{x} \mathrm{g}$ and $4^{\circ} \mathrm{C}$ for 
Table I. Reverse transcription-quantitative polymerase chain reaction primers used.

\begin{tabular}{|c|c|c|}
\hline Primers & Sequences & Target gene \\
\hline LPA1-F & 5'-TGCTTGGGGCCTTTATCATC-3' & LPA1 \\
\hline LPA1-R & 5'-TTCTCATAGGCCAGCACGTC-3' & \\
\hline LPA2-F & 5'-ACACTTCTGGCACTGCCTCT-3' & LPA2 \\
\hline LPA2-R & 5'-AGGCTGAGTGT GTCTCTCG-3' & \\
\hline LPA3-F & 5'-TAGGGGCGTTTGTGGTATGC-3' & LPA3 \\
\hline LPA3-R & 5'-CACCTTTTCACATGCTGCAC-3' & \\
\hline LPA4-F & 5'-CCATGGGTGACAGAAGATTCA-3' & LPA4 \\
\hline LPA4-R & 5'-GGCAGTAGCATTGCCCAAC-3' & \\
\hline LPA5-F & 5'-TCTCTGCTGCTGATGAAGCTG-3' & LPA5 \\
\hline LPA5-R & 5'-AGGGAGGTCATGGGAATGTG-3' & \\
\hline LPA6-F & 5'-CCAGCGGAAATTTTACAGCA-3' & LPA6 \\
\hline LPA6-R & 5'-GCAAATTATCTGGATCTTTGGATG-3' & \\
\hline Notch1-F & 5'-GCTTGTGGTAGCAAGGAAGC-3' & Notch1 \\
\hline Notch1-R & 5'-CCACATTCAAGTGGCTGATG-3' & \\
\hline GAPDH-F & 5'-AAGGTGAAGGTCGGAGTC-3' & GAPDH \\
\hline GAPDH-R & 5'-TGTAGTTGAGGTCAA TGAAGG-3' & \\
\hline
\end{tabular}

LPA1-6, lysophosphatidic acid receptor 1-6; F, forward; R, reverse.

10 min. Co-IP assays were performed using a Co-IP kit (Pierce; Thermo Fisher Scientific, Inc.) according to the manufacturer's protocol. Briefly, a total of $200 \mu \mathrm{g}$ protein was incubated with LPA 2 and Notch1 antibodies (detailed below) at $4^{\circ} \mathrm{C}$ for $12 \mathrm{~h}$. Immune complexes were precipitated with protein $\mathrm{A} / \mathrm{G}$ sepharose beads and the complexes were centrifuged at $400 \mathrm{x} \mathrm{g}$ at $4^{\circ} \mathrm{C}$ for $10 \mathrm{~min}$. Finally, immune complexes were analyzed by western blotting.

Antibodies. The commercial primary antibodies used in the present study are as follows: Anti-EDG4 antibody (cat. no. 135980; Abcam, Cambridge, MA, USA), anti-Notch1 antibody (cat. no. 3608; Cell Signaling Technology, Inc., Danvers, MA, USA), anti-Hes-1 antibody (cat. no. 11988; Cell Signaling Technology, Inc.), anti-Akt antibody (cat. no. 4691; Cell Signaling Technology, Inc.), anti-p-Akt antibody (cat. no. 13038; Cell Signaling Technology, Inc.), anti-E-Cadherin antibody (cat. no. A42; Cell Signaling Technology, Inc.), anti-vimentin antibody (cat. no. 5741; Cell Signaling Technology, Inc.), anti-F-actin antibody (cat. no. 130935; Abcam) and anti- $\beta$-actin antibody (cat. no. 608407; Thermo Fisher Scientific, Inc.). All the primary antibodies were diluted to $1: 1,000$. The secondary antibodies used in the present study were as follows: HRP-labeled goat anti-rabbit IgG (cat. no. 97051; Abcam) and HRP-labeled goat anti-mouse IgG (cat. no. 205719; Abcam). The secondary antibodies were diluted to 1:5,000.

Wound scratch assay. GES-1 and SGC-7901 cells were seeded in 6-well plates and cultured to $70-80 \%$ confluence. Scrape lines were made using $200 \mu \mathrm{l}$ pipette tips, as described previously (35); the initial wound width was at least $500 \mathrm{~nm}$. Plates were washed twice with phosphate buffered saline (PBS) and re-incubated with different doses of LPA. Photographs were taken at $0,6,12$ and $24 \mathrm{~h}$ post-LPA treatment. The wound healing rate $=[$ Edge distance $(0 \mathrm{~h})$-Edge distance $(\mathrm{n} \mathrm{h})] /$ Edge distance $(0 \mathrm{~h}) \times 100 \%$.

Transwell migration and invasion assays. A total of $2 \times 10^{5}$ GES-1 or SGC-7901 cells were suspended in serum-free RPMI-1640 medium with or without Matrigel (BD Biosciences, Franklin Lakes, NJ, USA; diluted in a 1:8 proprotion) in the upper chambers (Corning Inc., Corning, NY, USA) and LPA or RPMI 1640 medium containing 5\% FBS were also added into 24-well plates (lower chambers), and the incubation time was $24 \mathrm{~h}$. Cells were then washed with PBS, fixed using $4 \%$ paraformaldehyde for $15 \mathrm{~min}$ at the room temperature and stained using $0.1 \%$ crystal violet for $10 \mathrm{~min}$ at the room temperature. The cells that were unattached to the trans membrane were removed using cotton swabs, as previously described (25). The cells that passed through the membrane and were located in five randomly selected light microscopic fields (magnification, $\mathrm{x} 200)$ per chamber were then imaged and counted.

MTS assay. GES-1 and SGC-7901 cells were seeded in 96-well plates at a density of $1 \times 10^{3}$ per well. Following incubation for $24 \mathrm{~h}$, the cells were washed using PBS and treated with different concentrations of LPA. Cell Titer96 ${ }^{\circledR}$ AQueous One Solution reagent (Promega Corporation) was added continuously, according to the manufacturer's protocol. Following incubation for $3 \mathrm{~h}$ at $37^{\circ} \mathrm{C}$ and $5 \% \mathrm{CO}_{2}$, the absorbance value (optical density value) at $490 \mathrm{~nm}$ were recorded on a microplate reader and cell viability was calculated, using the following formula: [Cell viability $(\%)=(\mathrm{A}$ experiment $-\mathrm{A}$ blank)/(A control-A blank) x100].

Transfection with small interfering RNA (siRNA). SGC-7901 cells cultured in 6-well plates at a density of $2 \times 10^{5}$ cells per well. 
Table II. siRNAs used in the present study.

\begin{tabular}{ll} 
siRNA & \multicolumn{1}{c}{ Sequence } \\
\hline Negative control & Sense: 5'-AUUGACCAGUGAGUUGGCCTT-3' \\
si-LPA2 & Antisense: 5'-GCGAGUCUGUCCACUAUACTT-3' \\
& Sense: 5'-AUUGACCAGUGAGUUGGCCTT-3' \\
si-Notch1 & Antisense: 5'-GCGAGUCUGUCCACUAUACTT-3' \\
& Sense: 5'-UCGCAUUGACCAUUCAAACUGGUGG-3' \\
& Antisense: 5'-CCACCAGUUUGAAUGGUCAAUGCGA-3'
\end{tabular}

siRNA/si-, small interfering RNA; LPA2, lysophosphatidic acid receptor 2.

When the cells reached 70-80\% confluence, $150 \mathrm{nM} \mathrm{LPA} 2$ or Notch1 siRNA (Shanghai GenePharma Co., Ltd., Shanghai, China) were transfected into cells, and Lipofectamine $2000^{\circledR}$ (Thermo Fisher Scientific, Inc.) was used, according to the manufacturer's protocol. The cells were incubated at $37^{\circ} \mathrm{C}$ in $5 \% \mathrm{CO}_{2}$ and saturated humidity for $24 \mathrm{~h}$. In total, $150 \mathrm{nM}$ negative control (NC) siRNA was used as the negative control. The sequences of the siRNAs are listed in Table II.

Indirect immunofluorescence microscopy assay (IFA). The IFA assay was performed as described previously (36). Briefly, SGC-7901 cells were plated into Nunc glass-bottom dishes (Thermo Fisher Scientific, Inc.) and treated with LPA for $24 \mathrm{~h}$ or fresh RPMI-1640 medium containing 10\% FBS. Cells were washed at $37^{\circ} \mathrm{C}$ with PBS and fixed using $4 \%$ paraformaldehyde for $15 \mathrm{~min}$ at room temperature. Cells were then incubated with fluorescein isothiocyanate (FITC)-phalloidin (1:200; Beijing Solarbio Science \& Technology Co., Ltd.) overnight at $4^{\circ} \mathrm{C}$. Then, cells were incubated with DAPI for $30 \mathrm{sec}$ at the room temperature. Dishes were analyzed and imaged on a fluorescent microscope (magnification, x63).

Statistical analysis. Statistical analyses were performed using GraphPad Prism software 7 (GraphPad Software, Inc., La Jolla, CA, USA). Differences between experimental groups were assessed using one-way analysis of variance and Tukey's post-hoc test. Student's t-test was used to examine the statistical differences between two groups $\mathrm{P}<0.05$ was considered to indicate a statistically significant difference. The results are presented as the mean \pm the standard error of the mean.

\section{Results}

Determination of the experimental LPA concentration. To select the concentration of LPA that is able to induce metastasis and invasion, wound scratch assays, transwell migration and invasion assays were performed. SGC-7901 gastric cancer cells were selected as the experimental cells, and the normal gastric epithelial cells (GES-1) were selected as the control. The wound healing rate reached the maximum at an LPA concentration of $15 \mu \mathrm{M}$ (Fig. 1A and B). The number of SGC-7901 cells that traversed the membrane were significantly increased at $15 \mu \mathrm{M}$ LPA in the transwell migration and invasion assays compared with the control (untreated) group $(\mathrm{P}<0.01$; Fig. 1C-H). MTS assays were also performed to confirm the impact of LPA on the viability of cells (Fig. 1I) and it was revealed that $15 \mu \mathrm{M}$ LPA did not affect the viability of the cells. Therefore, the $15 \mu \mathrm{M}$ LPA and a duration time is $24 \mathrm{~h}$ were used for subsequent experiments.

LPA stimulates LPA2, activating the Notch signaling pathway in SGC-7901 cells. A previous study revealed that the migration behavior of SGC-7901 gastric cancer cells was regulated by LPA via the LPA/LPA2/Gq/11/p38 pathway (37). However, whether LPA induced the migration and invasion of SGC-7901 cells by LPA 2 and Notch pathways remained unknown. The present study therefore evaluated the mRNA expression levels of LPA1-6 in SGC-7901 and GES-1 cells using RT-qPCR. The expression of LPA2 was most significantly enhanced in SGC-7901 cells compared with GES-1 cells ( $\mathrm{P}<0.05$; Fig. S1).

To identify whether the Notch pathway was involved in the LPA-induced migration and invasion of SGC-7901 cells, the mRNA levels and the abundance of LPA2 and Notch1 in SGC-7901 and GES-1 cells were compared. It was revealed that the expression of LPA2 and Notch1 mRNA and protein levels were significantly higher in SGC-7901 cells compared with GES-1 cells $(\mathrm{P}<0.05$; Fig. $2 \mathrm{~A}$ and $\mathrm{B})$. In addition, the SGC-7901 cells were incubated with LPA for $24 \mathrm{~h}$, cells were collected and analyzed by western blotting. The results revealed that the abundance of LPA2, Notch1, Hes-1 and phosphorylated-Akt were significantly enhanced in LPA-treated cells compared with that in LPA-untreated cells $(\mathrm{P}<0.05$; Fig. 2C). In addition, the mRNA levels of LPA2 and Notch1 were also signficantly increased following LPA treatment ( $\mathrm{P}<0.05$; Fig. 2D). Collectively, these results indicate that LPA activates LPA2 and Notch signaling pathways.

LPA induced EMT and remodeling of the cytoskeleton in $S G C-7901$ cells. The progress of EMT is crucial for the migration and invasion in numerous malignant tumor types (38). Under an oncogenic stimulant, the expression of E-cadherin is decreased, whereas the expression of vimentin is increased, resulting in an untethering of cell-cell adhesion. In addition, cellular morphology and fibrous actin (F-actin) will be altered during EMT (39).

To investigate the EMT progress, SGC-7901 cells cultured in 6-well plates were treated with or without LPA for $24 \mathrm{~h}$. The collected cells were analyzed by western blotting and IFA. The results revealed that the abundance of E-cadherin was significantly reduced, while the expression of vimentin was 

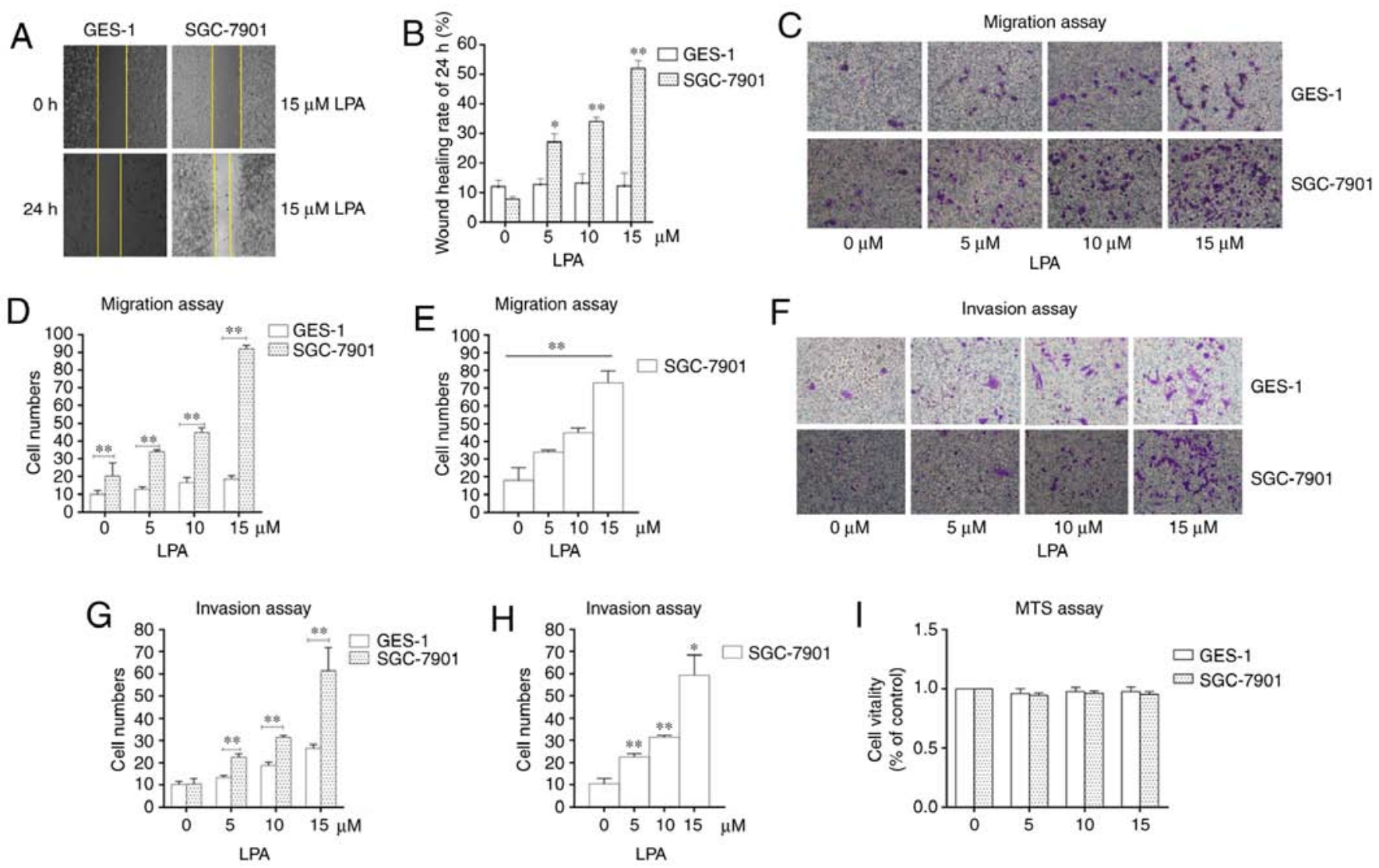

Figure 1. Identifying the experimental concentration of LPA. (A) Wound healing assays were performed using SGC-7901 and GES-1 cells which were incubated with 0,5, 10 and $15 \mu \mathrm{M}$ LPA. Photographs were obtained at 0,6,12 and $24 \mathrm{~h}$ after LPA treatment. (B) Quantified wound healing rate. (C) Migration assay for SGC-7901 and GES-1 cells traeted with different doses $(0,5,10$ and $15 \mu \mathrm{M})$ of LPA. (D and E) Counting the number of transmembrane cells in the migration assay. (F) Invasion assay for SGC-7901 and GES-1 cells traeted with different doses $(0,5,10$ and $15 \mu \mathrm{M})$ of LPA. (G and H) Counting the number of transmembrane cells in the invasion assay. (I) Cells were seeded in 96-well plates, and the monolayer cells were treated with different doses of LPA for $24 \mathrm{~h}$. The cytotoxicity of LPA was measured using MTS assays. These results are representative of three independent experiments. ${ }^{*}<0.05$ and ${ }^{* *} \mathrm{P}<0.01$ with comparisons shown by lines. LPA, lysophosphatidic acid.

significantly increased compared with untreated cells $(\mathrm{P}<0.05$; Fig. 3A). The IFA assay also revealed numerous filaments (cytoskeletal fibers) on the surface of cells and filamentous bulges (pseudopodium) surrounding LPA-treated cells (Fig. 3B). To confirm this effect, the present study analyzed the expression of F-actin and revealed that its levels were significantly increased in LPA-treated SGC-7901 cells ( $\mathrm{P}<0.01$; Fig. 3C). Collectively, these results indicated that LPA induces EMT progression and remodels the cytoskeleton of SGC-7901 cells.

Effects of LPA2 knockdown on cellular functions induced by LPA treatment in SGC-7901 cells. LPA2 is a mediator of the biological behaviors of numerous cancer cell types $(40,41)$. To investigate the functions of LPA2 on LPA-induced SGC-7901 cells, cells were transfected with LPA2 or NC siRNA for $24 \mathrm{~h}$, then treated with or without LPA. The cells were collected and analyzed by western blotting, qPCR, IFA, transwell migration and invasion assays. The results revealed that the expression of LPA2, Notch1, Hes-1 and Akt were significantly decreased in the LPA2 siRNA-transfected cells compared with that in the NC siRNA-transfected cells $(\mathrm{P}<0.05)$. In addition, the expression of LPA2, Notch1, Hes-1 and p-Akt were enhanced following LPA treatment (Fig. 4A and B). The transwell migration (Fig. 4C) and invasion assays (Fig. 4D) revealed that the cells that transited membranes were significantly fewer in the si-LPA 2 group compared with that in the NC group $(\mathrm{P}<0.01)$. When treated with LPA, the cell numbers that transited the chambers were higher in the NC group compared with the si-LPA2 group.

These results also demonstrated that the abundance of E-cadherin in the si-LPA2 group was markedly increased $(\mathrm{P}<0.05)$, while vimentin was decreased compared with the $\mathrm{NC}$ group $(\mathrm{P}<0.05)$. In addition, E-cadherin was decreased and vimentin was increased following LPA treatment (Fig. 4E). IFA revealed that the cytoskeleton (Fig. 4F and G) and expression of F-actin (Fig. 4H) were significantly enhanced in the NC siRNA-transfected cells following LPA treatment compared with the LPA un-treated group $(\mathrm{P}<0.05)$, and no clear changes to the cytoskeleton (Fig. $4 \mathrm{~F}$ and $\mathrm{G}$ ) or in the expression of F-actin (Fig. 4H) were observed in the LPA2 siRNA-transfected cells when treated with or without LPA. Altogether, these results indicated that LPA2 served a key function in mediating EMT progression and regulating the cytoskeleton of SGC-7901 cells.

Effects of Notchl knockdown on cellular functions induced by LPA treatment in SGC-7901 cells. The expression of Notch1 was reduced in SGC-7901 cells with downregulated LPA2. Therefore, the present study investigated whether Notch1 may affect the migration and invasion of SGC-7901 cells. To do so, Notch1 or NC siRNA was transfected into SGC-7901 cells 

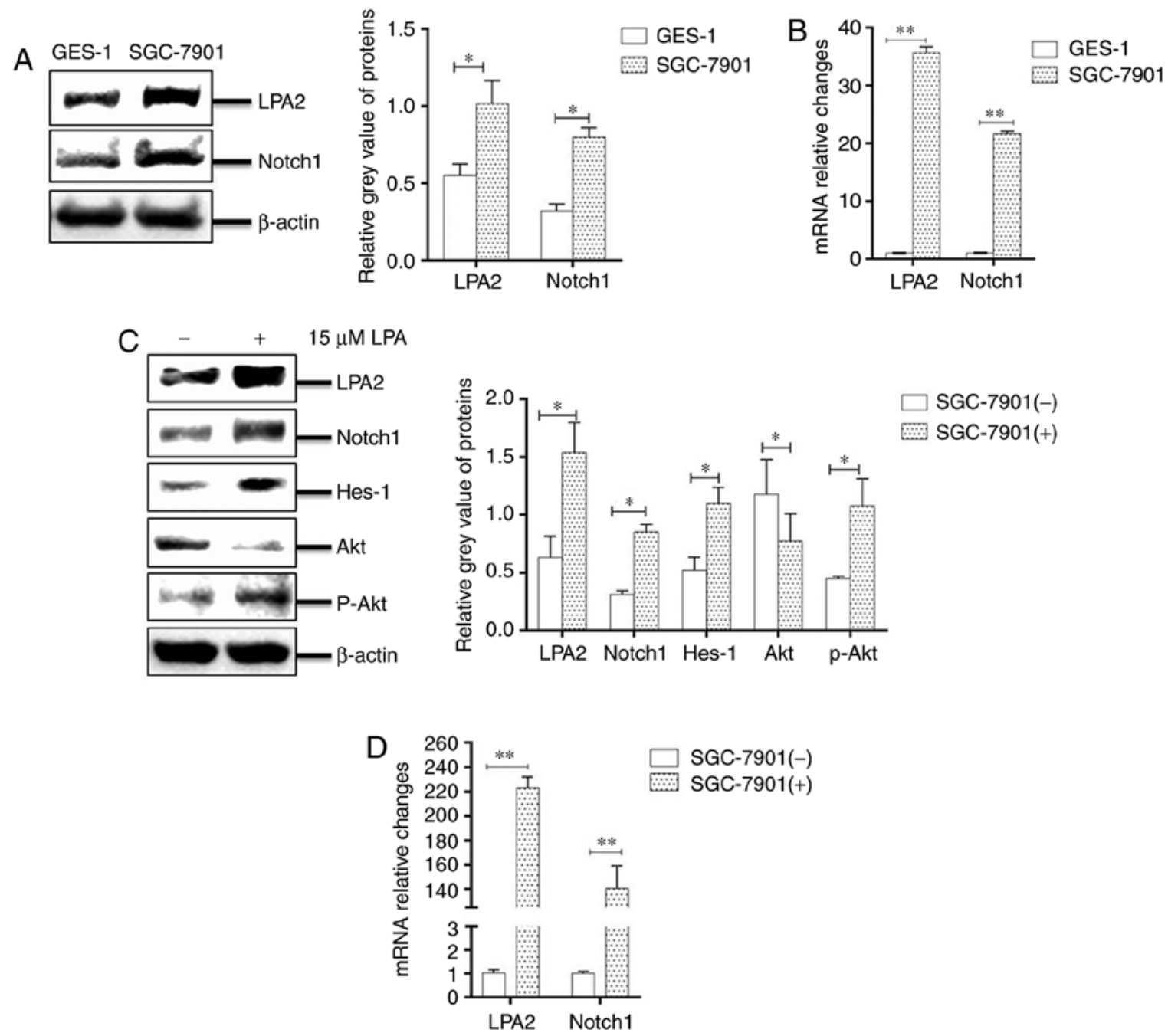

Figure 2. LPA stimuluates LPA2, activating the Notch signaling pathway in SGC-7901 cells. Expression of LPA2 and Notch1 were determined in GES-1 and SGC-7901 cells by (A) western blotting and (B) RT-qPCR. Expression of LPA2, Notch1, Hes-1, Akt and p-Akt were determined in SGC-7901 cells by (C) western blotting, and (D) the mRNA levels of LPA2 and Notch1 were determined by RT-qPCR. (-), cells treated without $15 \mu \mathrm{M}$ LPA; (+), cells treated with $15 \mu \mathrm{M}$ LPA. The blots with tracks form different exposures. These results are representative of three independent experiments. ${ }^{*} \mathrm{P}<0.05$ and ${ }^{* * *} \mathrm{P}<0.01$ with comparisons shown by lines. LPA, lysophosphatidic acid; RT-qPCR, reverse transcription-quantitative polymerase chain reaction; Hes-1, Hes Family BHLH Transcription Factor 1; Akt, protein kinase B; p-, phosphorylated.

and then treated with or without LPA. The collected cells were analyzed by western blotting, qPCR, IFA, transwell migration and invasion assays. The results revealed that the expression of LPA2, Notch1, Hes-1 and Akt were decreased in the Notch1 siRNA-transfected cells compared with that in the NC-siRNA transfected cells. In addition, the expression of LPA2, Notch1, Hes-1 and p-Akt were enhanced following LPA treatment $(\mathrm{P}<0.05$; Fig. 5A and $\mathrm{B})$. The present study additionally investigated the function of Notch1 on migration and invasion in vitro. The cells which transited the bottom of chambers were significantly fewer in si-Notch1 group compared with the NC group $(\mathrm{P}<0.01)$, and the trans-membrane cells that were counted were elevated in the NC group once LPA was added (Fig. 5C and D).

The abundance of E-cadherin in the si-Notch1 group was increased and vimentin was decreased, compared with the NC group, while the expression of E-cadherin was decreased and vimentin was increased, following treatment with LPA $(\mathrm{P}<0.05$; Fig. 5E). IFA revealed that the cytoskeleton (Fig. 5F and G) and expression of F-actin (Fig. 5H) were significantly increased in the NC siRNA-transfected cells following LPA treatment $(\mathrm{P}<0.05)$, and no substantial changes to the cytoskeleton (Fig. 5F and G) or F-actin expression (Fig. 5H) in the si-Notch1 group occured. Altogether, these results suggest that Notch1 functions as a mediator in regulating the EMT progress and regulating the cytoskeleton of SGC-7901 cells.

LPA2 interacts with Notchl. To investigate a potential interaction between LPA2 and Notch1, a co-IP assay was performed. SGC-7901 cells cultured in 60-mm-dishes were treated with or without $15 \mu \mathrm{M}$ LPA for $24 \mathrm{~h}$. The cells were lysed and the lysates were collected, then the compounds were immunoprecipitated with anti-LPA 2 antibody and analyzed by western blotting. LPA2 pulled down Notch1 (Fig. 6A). A reverse immunoprecipitation experiment was also performed using an anti-Notch1 antibody, which revealed that Notch1 also pulled down LPA2 (Fig. 6B). In addition, LPA promoted the interaction between LPA2 and Notch1 (Fig. 6A and B). Altogether, these results indicate that the interaction between LPA2 and Notch1 is involved in the migration and invasion of SGC-7901 cells. 

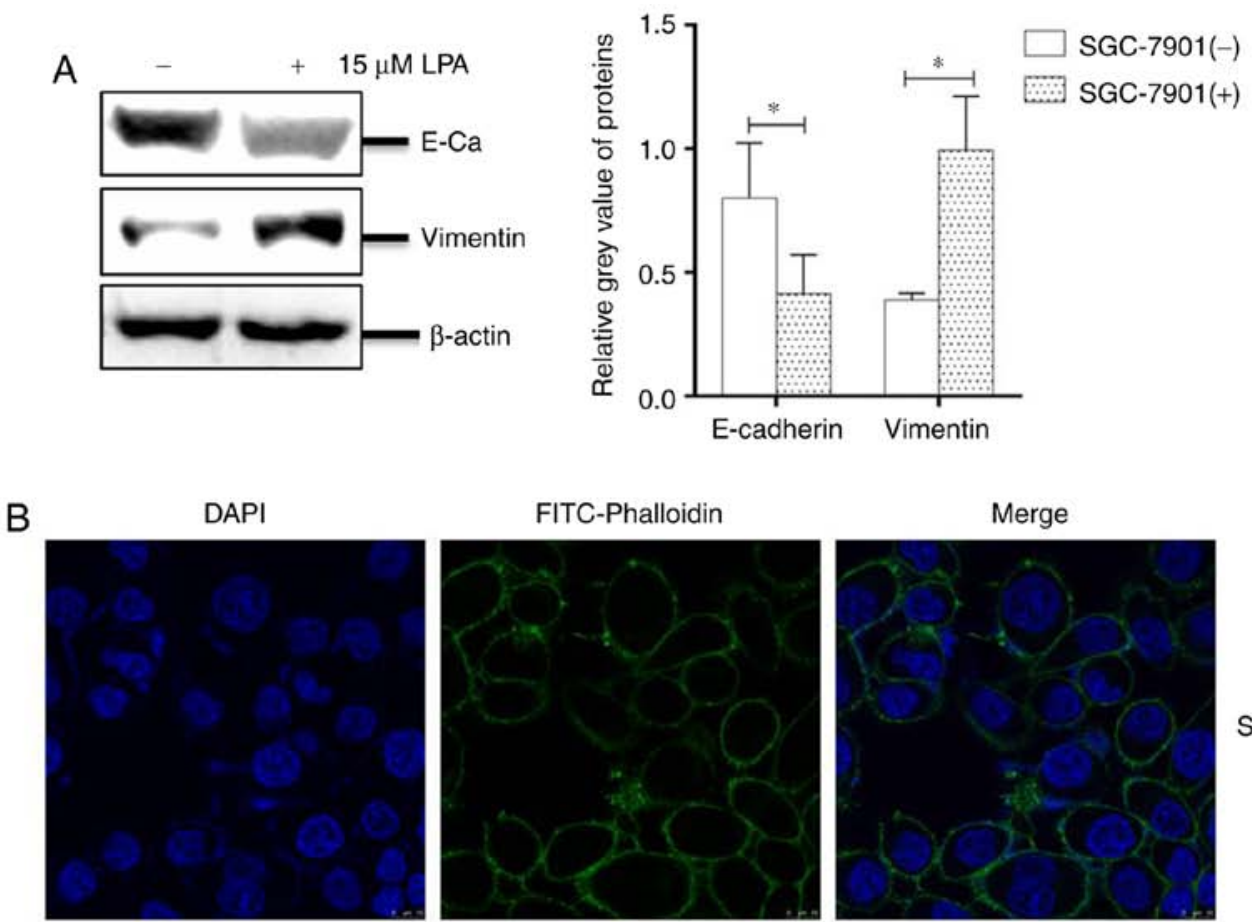

SGC-7901(-)
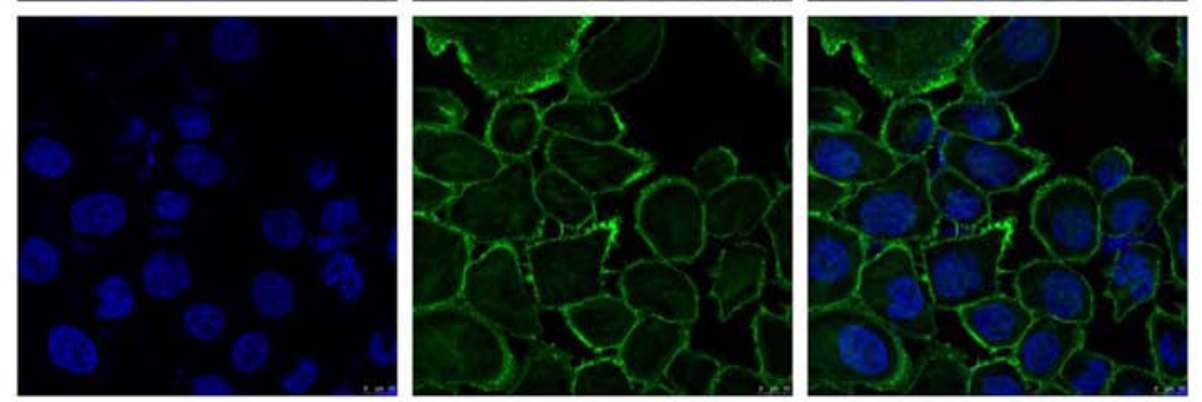

SGC-7901(+)
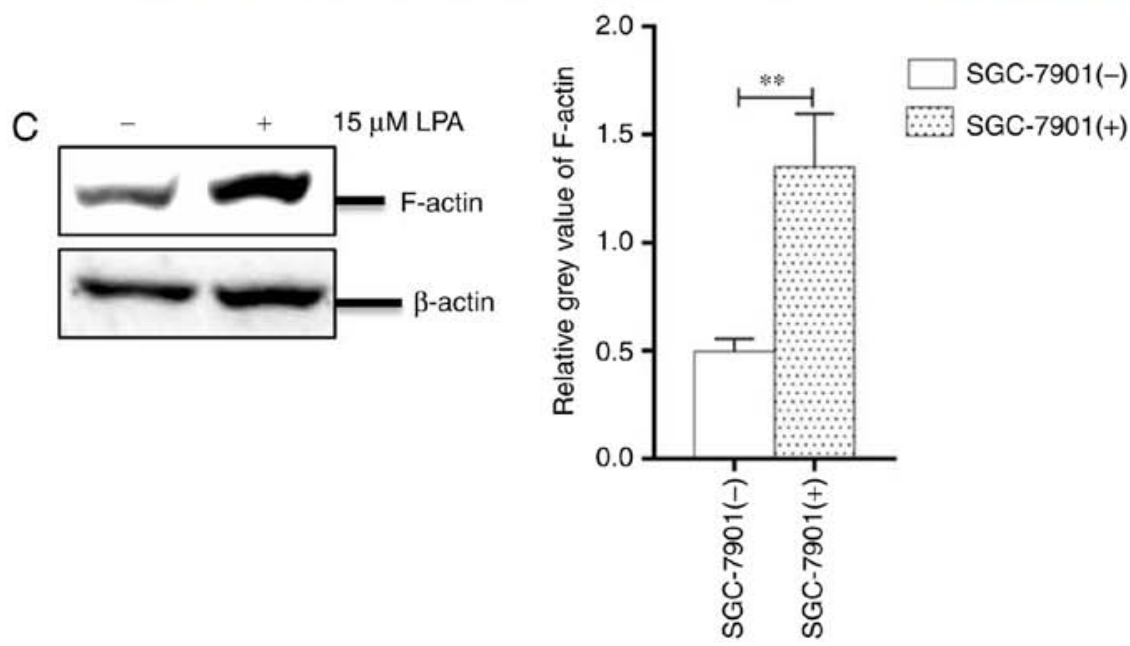

Figure 3. LPA induced epithelial-to-mesenchymal transition and remodeled the cytoskeleton of SGC-7901 cells. (A) Expression levels of E-cadherin and vimentin in SGC-7901 cells were analyzed by western blotting. (B) SGC-7901 cells were plated into Nunc glass-bottom dishes, and the monolayer cells were treated with or without LPA for $24 \mathrm{~h}$. Cells were then fixed and stained with FITC-phalloidin and DAPI. Cells were observed and imaged on a fluorescence microscope. (C) Expression of F-actin in SGC-7901 cells treated with or without $15 \mu \mathrm{M}$ LPA for $24 \mathrm{~h}$ was determined by western blotting. (-), cells treated without $15 \mu \mathrm{M} \mathrm{LPA} ;(+)$, cells treated with $15 \mu \mathrm{M} \mathrm{LPA}$. The blots with tracks form different exposures. These results are representative of three independent experiments. ${ }^{*} \mathrm{P}<0.05$ and ${ }^{* *} \mathrm{P}<0.01$ with comparisons shown by lines. LPA, lysophosphatidic acid; E-Ca, E-cadherin; FITC, fluorescein isothiocyanate.

\section{Discussion}

To date, numerous studies have indicated that LPA is at high levels in a multitude of malignant tumor types, including ovarian cancer, liver cancer and oral squamous cell carci- noma (42-44). LPA may also promote tumor angiogenesis, providing nutrients to tumor tissues, rebuild the cytoskeleton and promote the motor ability of tumor cells. LPA also functions as a biomarker for gastric cancer cases with metastasis (45). 

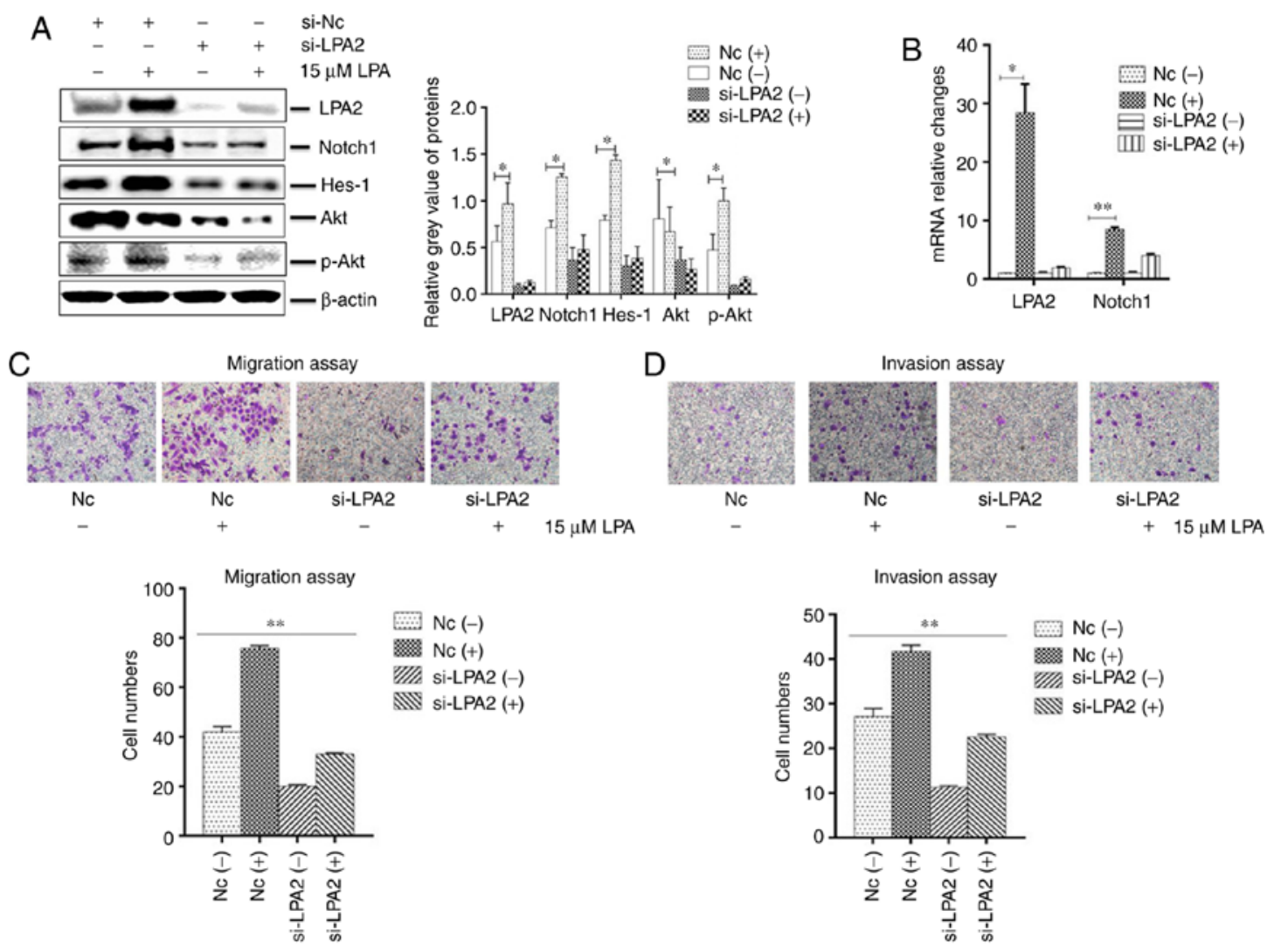

E
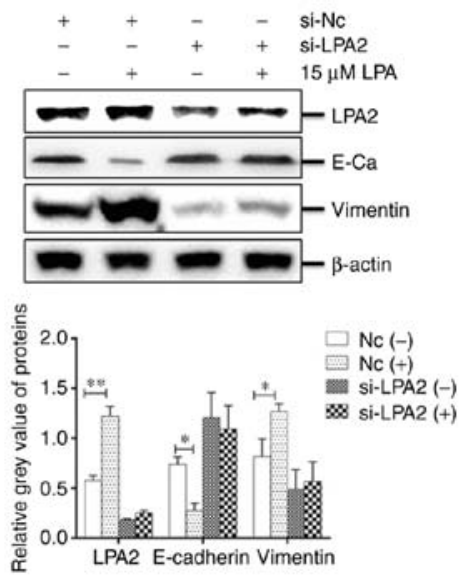

F

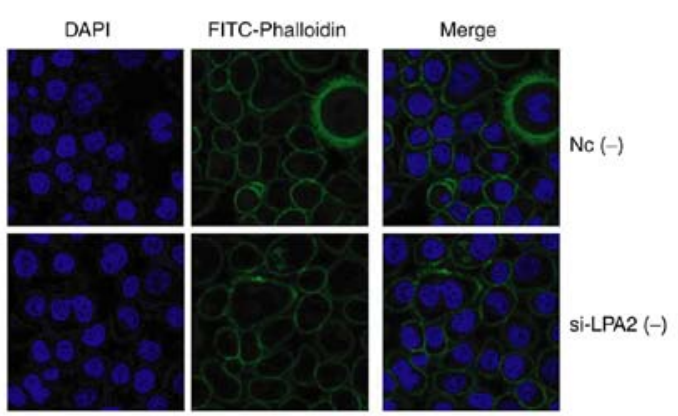

G DAPI
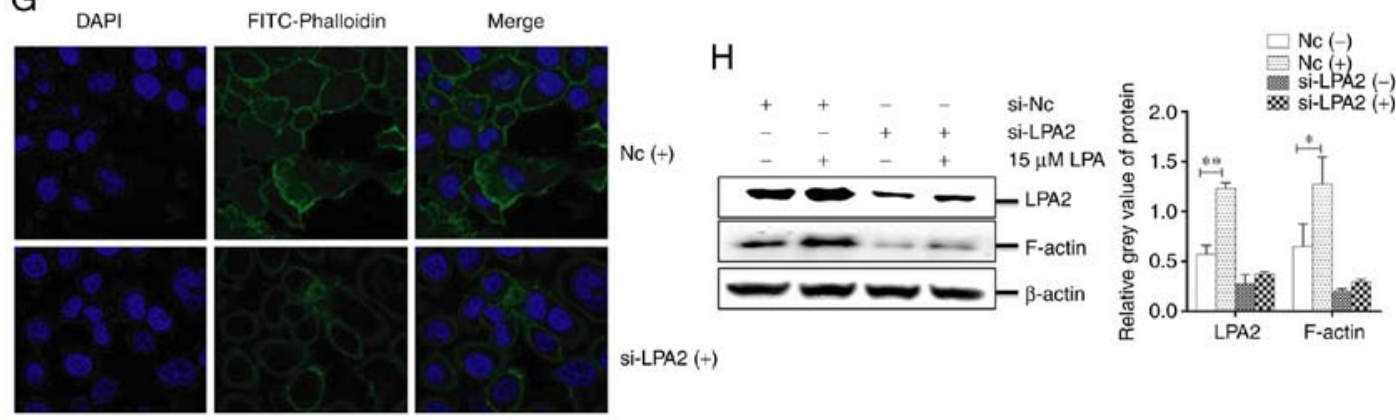

Si-LPA2 (+)

Figure 4. Effects of LPA2 knockdown on cellular functions induced by LPA treatment in SGC-7901 cells. SGC-7901 cells were seeded in 6-well plates, and the monolayer cells were transfected with $150 \mathrm{nM} \mathrm{LPA} 2$ or NC siRNA for $24 \mathrm{~h}$. Following transfection cells were then treated with or without $15 \mu \mathrm{M} \mathrm{LPA}$ for $24 \mathrm{~h}$. Cells were then collected and analysed by (A) western blotting and (B) reverse transcription-quantitative polymerase chain reaction. (C) Transwell migration and (D) invasion assays were performed. (E) Expression of E-Cadherin and vimentin by western blotting. (F and G) Similar RNA transfection was performed as described above. Following $24 \mathrm{~h}$ transfection, cells were treated with or without $15 \mu \mathrm{M} \mathrm{LPA}$ for $24 \mathrm{~h}$. Then indirect immunofluorescence microscopy assay experiments were performed. (H) Similar transfections were performed as described above, and cells cultured in 6-well plates were treated with or without $15 \mu \mathrm{M}$ LPA for $24 \mathrm{~h}$. Cells were then collected and the expression of F-actin was analysed by western blotting. (-), cells treated without $15 \mu \mathrm{M}$ LPA; (+), cells treated with $15 \mu \mathrm{M}$ LPA. The blots with tracks form different exposures. These results are representative of three independent experiments. "P<0.05 and ${ }^{* *} \mathrm{P}<0.01$ with comparisons shown by lines. LPA, lysophosphatidic acid; NC, negative control; Hes-1, Hes Family BHLH Transcription Factor 1; Akt, protein kinase B; p-, phosphorylated; si-, small interfering RNA; FITC, fluorescein isothiocyanate. 

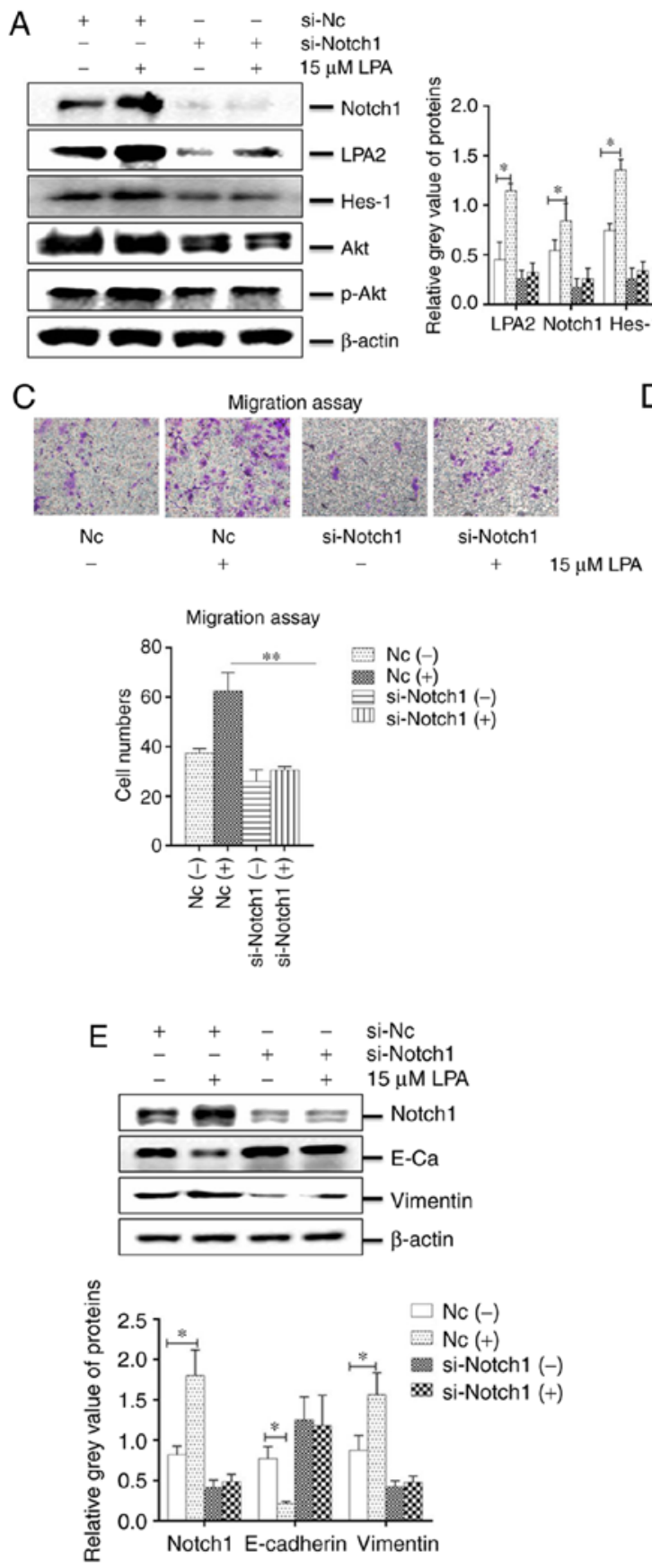

G

DAPI FITC-Phalloidin Merge

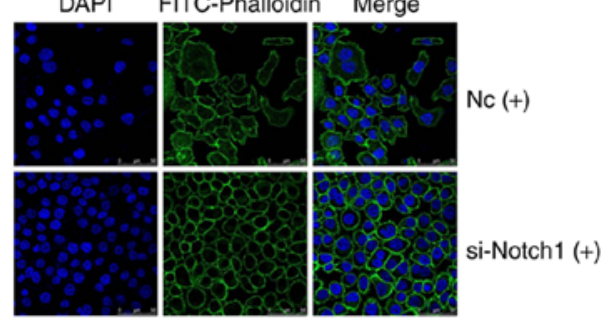

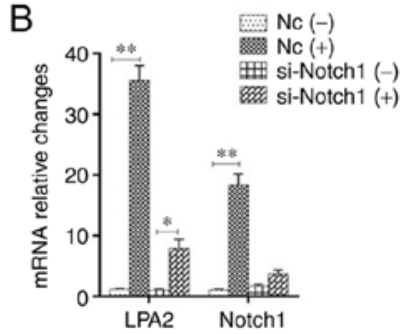
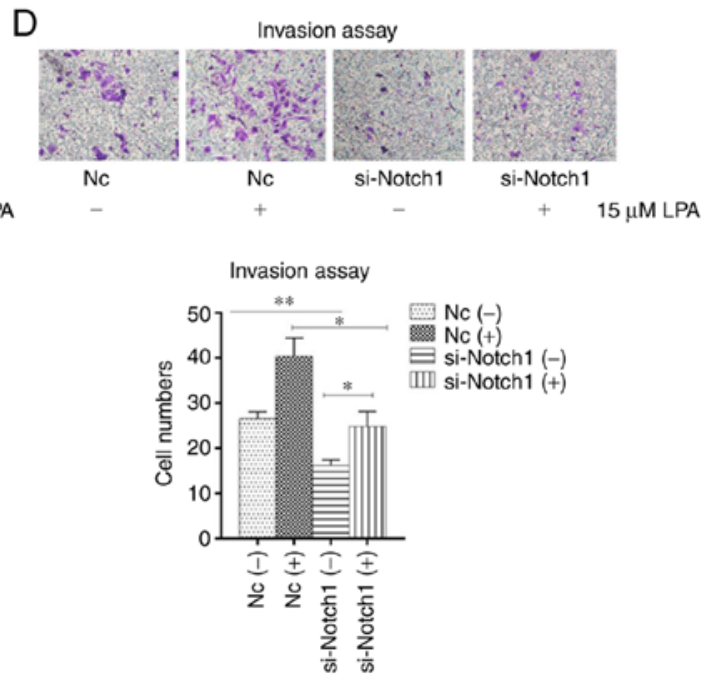

$\mathrm{F}$

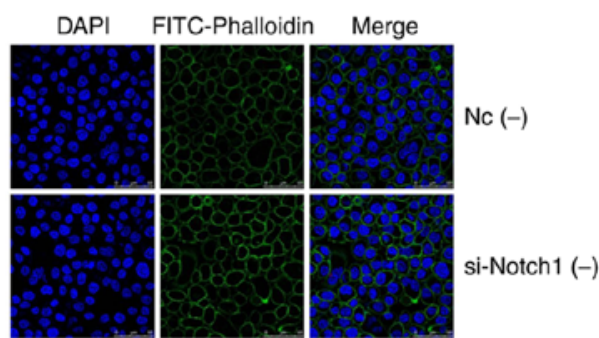

Figure 5. Effects of Notch1 knockdown on cellular functions induced by LPA treatment in SGC-7901 cells. SGC-7901 cells were seeded in 6-well plates, and the monolayer cells were transfected with $150 \mathrm{nM}$ Notch 1 or NC siRNA for $24 \mathrm{~h}$. Transfected cells were then treated with or without $15 \mu \mathrm{M}$ LPA for $24 \mathrm{~h}$, and collected for analysis by (A) western blotting and (B) reverse transcription-quantitative polymerase chain reaction. Transfections were performed as described above and (C) transwell migration and (D) invasion assays were performed. (E) Expression of E-Cadherin and vimentin were determined by western blotting. (F and G) Similar RNA transfection was performed as described above. Following $24 \mathrm{~h}$ transfection, cells were treated with or without $15 \mu \mathrm{M}$ LPA for 24 h. Then indirect immunofluorescence microscopy assay experiments were performed. (H) Expression of F-actin by western blotting. (-), cells treated without $15 \mu \mathrm{M}$ LPA; $(+)$, cells treated with $15 \mu \mathrm{M}$ LPA. The blots with tracks form different exposures. These results are representative of three independent experiments. ${ }^{*} \mathrm{P}<0.05$ and ${ }^{* *} \mathrm{P}<0.01$ with comparisons shown by lines. LPA, lysophosphatidic acid; NC, negative control; Hes-1, Hes Family BHLH Transcription Factor 1; Akt, protein kinase B; p-, phosphorylated; si-, small interfering RNA; E-Ca, E-cadherin; FITC, fluorescein isothiocyanate. 
A

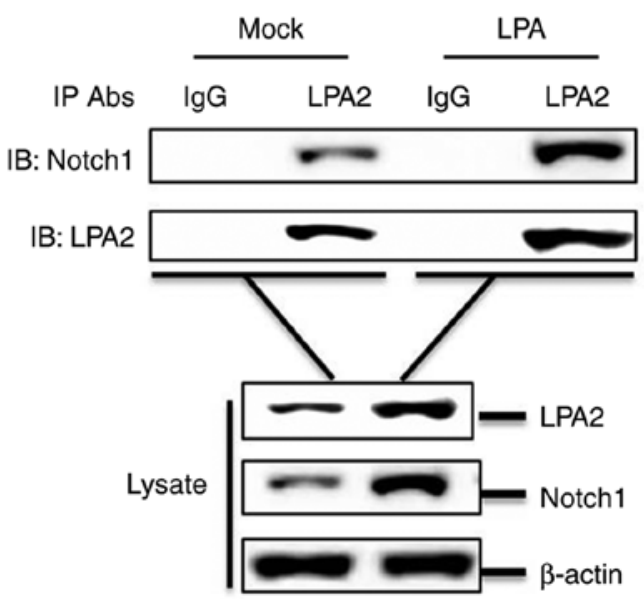

B

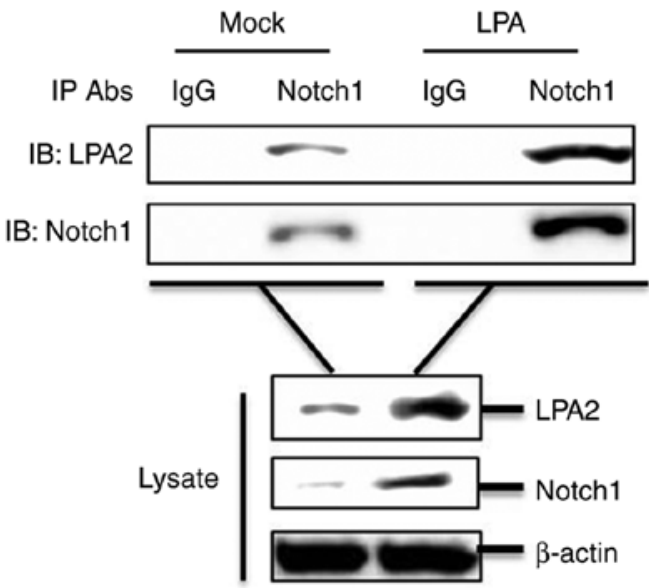

Figure 6. LPA2 interacts with Notch1. (A) SGC-7901 cells were cultured in 6-cm dishes. Monolayer cells were treated with or without $15 \mu$ M LPA for $24 \mathrm{~h}$. Following which, cells were lysed and the lysates were immunoprecipitated with rabbit anti-EDG4 antibody and subjected to western blotting. Whole cell lysates and IP antibody-antigen complexes were analyzed by immunoblotting using anti-lysophosphatidic acid receptor 2, anti-Notch1 or anti- $\beta$-actin antibodies. (B) Treatment and immunoprecipitation experiments were performed as described above. However, the lysates were immunoprecipitated with rabbit anti-Notch1 antibody and subjected to western blotting. Whole cell lysates and IP antibody-antigen complexes were analyzed by immunoblotting using anti-lysophosphatidic acid receptor 2 , anti-Notch1 or anti- $\beta$-actin antibodies. These results are representative of three independent experiments. LPA, lysophosphatidic acid; IgG, immunoglobulin G; IP, immunoprecipitation.

LPA2 is involved in numerous oncologic signal pathways, particularly in the microenvironment of rich-LPA (46). A previous study demonstrated that over-expressing LPA2 (with no treatment with LPA) may accelerate the proliferation, invasion, migration and anti-apoptosis of SGC-7901 cells (31). In the present study, the results indicated that the reduction of LPA2 (with no treatment with LPA) also affected the invasion and migration of SGC-7901 cells. Altogether, the results indicate that LPA2 alone may affect the aggressiveness of cells. Notch1 is a key element of the Notch pathway, and regulates the functions of numerous cancer cell phenotypes $(47,48)$. The Notch pathway is also involved in the drug-resistance of gastric cancer cells (49). Numerous factors are associated with the risk of gastric cancer disease-specific mortality, which may result from interacting or opposing cell signaling pathways. However, there are no clear links between LPA2 and Notch1.

EMT progression is a multi-step biological process and is characterized by a rebuilding of the cytoskeleton, allowing cancer cells to migrate and invade. The regulation of EMT relies on a complex network of signaling pathways (50). During EMT progression, cell-cell adhesion is affected by cytoskeleton alterations and cellular morphology is altered. Previous studies have revealed that Notch1 controls the EMT of breast cancer cells in a snail family transcriptional repressor 2-dependent manner (51), and that LPA2 meditates the cell-cell and cell-matrix of HEC1A cells (52). Nevertheless, the mechanisms by which LPA2 and Notch1 co-regulate EMT progression are not well known.

The LPA-LPA2 axis has been implicated in the pathology of human gastric cancer cells $(37,38,53)$, and the present study focused on the pathways via LPA2 and Notch1 induced migration and invasion of gastric cancer cells. In the present study, the results revealed that following LPA treatment, the expression of LPA2, Notch1 and Hes-1 were enhanced in SGC-7901 cells, and the phosphorylation of Akt was increased, which indicated that LPA may activate Notch pathway through LPA2. There are multiple chemokines in the microenvironment in which cells existed, which drives cells to transform into the mesenchymal phenotypes (54). Western blotting and IFA assays revealed that LPA triggered EMT progression by regulating cellular morphology, the cytoskeleton and pseudopods of SGC-7901 cells. In colon cancer cells, LPA2 was highly expressed in HCT116 cells, and when RNA interference was used to knockdown the LPA2 in HCT116 cells, the proliferation and tumor formation were attenuated (55). Another study revealed that the migration and invasion of ovarian cancer cells SKOV-3 were determined by LPA2, and the aggressiveness of SKOV-3 cells may be strengthened by the stimulation of LPA (56). Sun et al (57) indicated that overexpression Notch1 affected the progression of cervical cancer, and the reduction of Notch1 protein in the Hela, SiHa, C33A, Caski and HT-3 cells decreased the malignant behaviors of these cells. The present study contributed to the use of si-LPA2 and si-Notch1 siRNAs to identify the mechanisms and functions of LPA2 and Notch1. SGC-7901 cell migration and invasion were suppressed by LPA2 knockdown, similar to that observed with Notch1 downregulation. In the siRNA-transfected SGC-7901 cells, the expression of Hes-1 was reduced, and the process of Akt phsophorylation was inhibited, and there were no changes when LPA was added. The function of the Notch pathway was affected in the siRNAs transfected cells, and a series of detailed analyses indicated that LPA2 and Notch1 function as molecular switches in controlling the malignant behaviors of SGC-7901 gastric cancer cells.

Zang et al (49) revealed that the cleaved form of Notch1 may interact with $\beta$-catenin and promote the proliferation, migration and inhibition of cell apoptosis of gastric cancer cells. Another study revealed that LPA2-mediated signal transduction may be achieved through $\mathrm{G}$ protein-activated signaling cascades and the interacting partner-meditated signaling pathways (58). In the present study, Notch signaling was predicted to be a potential target of LPA by the endogenous 
gastric cancer cells network model, and the regulation of the LPA-LPA2-Notch pathway was hypothesized to serve a crucial function in the malignant behavior of SGC-7901 cells. So the present study focus on the association between LPA2 and Notch1 in SGC-7901 cells. To further verify our results, co-IP assays were used to confirm the interaction between LPA2 and Notch1. The results confirm that when exogenous LPA was added as a chemoattractant, the invasion and migration behaviors of SGC-7901 cells may be substantially promoted. The specific mechanism is that LPA binds to its receptor LPA2, and recruits Notch1 to accelerate EMT. In addition, the Notch pathway was also activated following LPA treatment, thus the malignant behaviors of the cells were further strengthened, and in the SGC-7901 cells in which the dual molecules were downregulated also demonstrated increased migration and invasion abilities, which may be attributed to the interaction between LPA2 and Notch1.

In the present study, the transwell migration and invasion assays revealed that the cells which transited chambers were substantially fewer in si-LPA 2 and si-Notch1 groups compared with si-LPA2 or si-Notch1 groups without treatment (Fig. S2A-B), which indicated that LPA2 and Notch1 may co-regulate the migration and invasion of SGC-7901 cells.

In conclusion, the present results provide a theoretical basis for the research of gastric cancer cells in molecular pathology, and further studies are required to determine the comprehensive mechanisms by which the combination of LPA2 with Notch1 function as diagnostic makers of gastric cancer.

\section{Acknowledgments}

Not applicable.

\section{Funding}

The present study was supported by grants from the Gansu Science Foundation (grant nos. 1606RJDA313 and 18JR3RA293) and the Lanzhou Science and Technology planning project (grant nos. 2017-4-64 and 2018-3-44).

\section{Availability of data and materials}

All data generated or analyzed during this study are included in this published article.

\section{Authors' contributions}

ZR, CZ, LM, XiZ, SS, DT, JX, YH, BW and FZ performed the experiments. $\mathrm{ZR}$ and $\mathrm{CZ}$ contributed to the data analysis and wrote the manuscript. $\mathrm{XuZ}$ and $\mathrm{HZ}$ contributed to the study design and concept, and contributed to the experiment materials. All authors read and approved the final manuscript.

\section{Ethics approval and consent to participate}

Not applicable.

\section{Patient consent for publication}

Not applicable.

\section{Competing interests}

The authors declare no that they have are no competing interests.

\section{References}

1. Charalampakis N, Economopoulou P, Kotsantis I, Tolia M, Schizas D, Liakakos T, Elimova E, Ajani JA and Psyrri A: Medical management of gastric cancer: A 2017 update. Cancer Med 7: 123-133, 2018.

2. Ferlay J, Soerjomataram I, Dikshit R, Eser S, Mathers C, Rebelo M, Parkin DM, Forman D and Bray F: Cancer incidence and mortality worldwide: Sources, methods and major patterns in GLOBOCAN 2012. Int J Cancer 136: E359-E386, 2015.

3. Tabuchi S: The autotaxin-lysophosphatidic acid-lysophosphatidic acid receptor cascade: Proposal of a novel potential therapeutic target for treating glioblastoma multiforme. Lipids Health Dis 14: $56,2015$.

4. Mills GB and Moolenaar WH: The emerging role of lysophosphatidic acid in cancer. Nat Rev Cancer 3: 582-591, 2003.

5. Kihara Y, Maceyka M, Spiegel S and Chun J: Lysophospholipid receptor nomenclature review: IUPHAR review $8 . \mathrm{Br}$ J Pharmacol 171: 3575-3594, 2014.

6. Lee SC, Fujiwara Y, Liu J, Yue J, Shimizu Y, Norman DD, Wang Y, Tsukahara R, Szabo E, Patil R, et al: Autotaxin and LPA 1 and LPA5 receptors exert disparate functions in tumor cells versus the host tissue microenvironment in melanoma invasion and metastasis. Mol Cancer Res 13: 174-185, 2015.

7. Li M, Xiao D, Zhang J, Qu H, Yang Y, Yan Y, Liu X, Wang J, Liu L, Wang J and Duan X: Expression of LPA2 is associated with poor prognosis in human breast cancer and regulates HIF-1 $\alpha$ expression and breast cancer cell growth. Oncol Rep 36: 3479-3487, 2016.

8. Enooku K, Uranbileg B, Ikeda H, Kurano M, Sato M, Kudo H, Maki H, Koike K, Hasegawa K, Kokudo N and Yatomi Y: Higher LPA2 and LPA6 mRNA levels in hepatocellular carcinoma are associated with poorer differentiation, microvascular invasion and earlier recurrence with higher serum autotaxin levels. PLoS One 11: e0161825, 2016.

9. Yun CC, Sun H, Wang D, Rusovici R, Castleberry A, Hall RA and Shim H: LPA2 receptor mediates mitogenic signals in human colon cancer cells. Am J Physiol Cell Physiol 289: C2-C11, 2005.

10. Mukherjee A, Ma Y, Yuan F, Gong Y, Fang Z, Mohamed EM, Berrios E, Shao H and Fang X: Lysophosphatidic acid up-regulates hexokinase II and glycolysis to promote proliferation of ovarian cancer cells. Neoplasia 17: 723-734, 2015.

11. Zhang R, Wang J, Ma S, Huang Z and Zhang G: Requirement of Osteopontin in the migration and protection against Taxolinduced apoptosis via the ATX-LPA axis in SGC7901 cells. BMC Cell Biol 12: 11, 2011.

12. Venkatraman G, Benesch MG, Tang X, Dewald J, McMullen TP and Brindley DN: Lysophosphatidate signaling stabilizes Nrf2 and increases the expression of genes involved in drug resistance and oxidative stress responses: Implications for cancer treatment. FASEB J 29: 772-785, 2015.

13. Yamashita H, Kitayama J, Shida D, Ishikawa M, Hama K, Aoki J, Arai H and Nagawa H: Differential expression of lysophosphatidic acid receptor- 2 in intestinal and diffuse type gastric cancer. J Surg Oncol 93: 30-35, 2006.

14. Gu C, Wang F, Zhao Z, Wang H, Cong X and Chen X: Lysophosphatidic acid is associated with atherosclerotic plaque instability by regulating NF- $\kappa \mathrm{B}$ dependent matrix metalloproteinase-9 expression via $\mathrm{LPA}_{2}$ in macrophages. Front Physiol 8: 266, 2017.

15. Dang TP: Notch, apoptosis and cancer. Adv Exp Med Biol 727: 199-209, 2012.

16. Hu YY, Zheng MH, Zhang R, Liang YM and Han H: Notch signaling pathway and cancer metastasis. Adv Exp Med Biol 727: 186-198, 2012.

17. Rizzo P, Osipo C, Foreman K, Golde T, Osborne B and Miele L: Rational targeting of Notch signaling in cancer. Oncogene 27: 5124-5131, 2008

18. Yamamoto S, Schulze KL and Bellen HJ: Introduction to Notch signaling. Methods Mol Biol 1187: 1-14, 2014.

19. Yuan Q, Chen X, Han Y, Lei T, Wu Q, Yu X, Wang L, Fan Z and Wang S: Modification of $\alpha 2,6$-sialylation mediates the invasiveness and tumorigenicity of non-small cell lung cancer cells in vitro and in vivo via Notch1/Hes1/MMPs pathway. Int J Cancer 143: 2319-2330, 2018. 
20. Wei G, Chang Y, Zheng J, He S, Chen N, Wang X and Sun X Notch1 silencing inhibits proliferation and invasion in SGC7901 gastric cancer cells. Mol Med Rep 9: 1153-1158, 2014.

21. Zhang $\mathrm{H}$, Wang $\mathrm{X}, \mathrm{Xu} \mathrm{J}$ and Sun Y: Notch1 activation is a poor prognostic factor in patients with gastric cancer. Br J Cancer 110: 2283-2290, 2014.

22. Yu XX, Hu Z, Shen X, Dong LY, Zhou WZ and Hu WH: IL-33 promotes gastric cancer cell invasion and migration Via ST2-ERK1/2 pathway. Dig Dis Sci 60: 1265-1272, 2015.

23. Li X, Liu S, Yan J, Peng L, Chen M, Yang J and Zhang G: The characteristics, prognosis, and risk factors of lymph node metastasis in early gastric cancer. Gastroenterol Res Pract 2018: 6945743, 2018.

24. Song Q, Ji Q and Li Q: The role and mechanism of $\beta$-arrestins in cancer invasion and metastasis (Review). Int J Mol Med 41: 631-639, 2018

25. Tian D, Li Y, Li X and Tian Z: Aloperine inhibits proliferation, migration and invasion and induces apoptosis by blocking the Ras signaling pathway in human breast cancer cells. Mol Med Rep 18: 3699-3710, 2018

26. Osborne CC, Perry KJ, Shankland M and Henry JQ: Ectomesoderm and EMT-related genes in spiralian development Dev Dyn 247, 2018. Doi: 1002/dvdy. 24667.

27. Nantajit D, Lin D and Li JJ: The network of epithelial-mesenchymal transition: Potential new targets for tumor resistance. J Cancer Res Clin Oncol 141: 1697-1713, 2015.

28. Yilmaz M and Christofori G: EMT, the cytoskeleton, and cancer cell invasion. Cancer Metastasis Rev 28: 15-33, 2009.

29. Chen Z, He J, Xing X, Li P, Zhang W, Tong Z, Jing X, Li L, Liu D, Wu Q and Ju H: Mn12Ac inhibits the migration, invasion and epithelial-mesenchymal transition of lung cancer cells by downregulating the $\mathrm{Wnt} / \beta$-catenin and PI3K/AKT signaling pathways. Oncol Lett 16: 3943-3948, 2018.

30. Zhao L, Pang A and Li Y: Function of GCN5 in the TGF- $\beta 1$-induced epithelial-to-mesenchymal transition in breast cancer. Oncol Lett 16: 3955-3963, 2018.

31. Linna MA, Chen Z, Zhi-Heng R, Xiao Z and Xu Z: Expression of LPA2 regulates the migration, invasion, proliferation, and apoptosis of gastric cancer SGC-7901 cells. Sci Technol Eng 18: 26-32, 2018.

32. Liu X, Sun K, Song A, Zhang X, Zhang X and He X: Curcumin inhibits proliferation of gastric cancer cells by impairing ATP-sensitive potassium channel opening. World J Surg Oncol 12: 389, 2014

33. Schmittgen TD and Livak KJ: Analyzing real-time PCR data by the comparative C(T) method. Nat Protoc 3: 1101-1108, 2008.

34. Zhu Z, Wang G, Yang F, Cao W, Mao R, Du X, Zhang X, Li C Li D, Zhang K, et al: Foot-and-mouth disease virus viroporin $2 \mathrm{~B}$ antagonizes RIG-I-mediated antiviral effects by inhibition of its protein expression. J Virol 90: 11106-11121, 2016.

35. Arranz-Valsero I, Soriano-Romaní L, García-Posadas L, López-García A and Diebold Y: IL-6 as a corneal wound healing mediator in an in vitro scratch assay. Exp Eye Res 125: 183-192, 2014.

36. Liu H, Xue Q, Cao W, Yang F, Ma L, Liu W, Zhang K, Liu X, Zhu $\mathrm{Z}$ and $\mathrm{Zheng} \mathrm{H}$ : Foot-and-mouth disease virus nonstructural protein $2 B$ interacts with cyclophilin A, modulating virus replication. FASEB J: June 15, 2018 (Epub ahead of print).

37. Yang D, Yang W, Zhang Q, Hu Y, Bao L and Damirin A: Migration of gastric cancer cells in response to lysophosphatidic acid is mediated by LPA receptor 2. Oncol Lett 5: 1048-1052, 2013.

38. De Craene B and Berx G: Regulatory networks defining EMT during cancer initiation and progression. Nat Rev Cancer 13: 97-110, 2013

39. Clay MR and Halloran MC: Cadherin 6 promotes neural crest cell detachment via F-actin regulation and influences active Rho distribution during epithelial-to-mesenchymal transition. Development 141: 2506-2515, 2014.

40. Takahashi K, Fukushima K, Fukushima N, Honoki K and Tsujiuchi T: Enhanced cellular functions through induction of LPA 2 by cisplatin in fibrosarcoma HT1080 cells. Mol Cell Biochem 431: 29-35, 2017.

41. Takahashi K, Fukushima K, Tanaka K, Minami K, Ishimoto K, Otagaki S, Fukushima N, Honoki K and Tsujiuchi T: Involvement of LPA signaling via LPA receptor-2 in the promotion of malignant properties in osteosarcoma cells. Exp Cell Res 369: $316-324,2018$
42. Wang H, Liu W, Wei D, Hu K, Wu X and Yao Y: Effect of the LPA-mediated CXCL12-CXCR4 axis in the tumor proliferation, migration and invasion of ovarian cancer cell lines. Oncol Lett 7: $1581-1585,2014$

43. Erstad DJ, Tager AM, Hoshida Y and Fuchs BC: The autotaxinlysophosphatidic acid pathway emerges as a therapeutic target to prevent liver cancer. Mol Cell Oncol 4: e1311827, 2017.

44. Aasrum M, Tjomsland V, Thoresen GH, De Angelis PM, Christoffersen T and Brusevold IJ: PI3K is required for both basal and LPA-induced DNA synthesis in oral carcinoma cells. J Oral Pathol Med 45: 425-432, 2016.

45. Zeng R, Li B, Huang J, Zhong M, Li L, Duan C, Zeng S, Huang J, Liu W, Lu J, et al: Lysophosphatidic acid is a biomarker for peritoneal carcinomatosis of gastric cancer and correlates with poor prognosis. Genet Test Mol Biomarkers 21: 641-648, 2017.

46. Singla A, Kumar A, Priyamvada S, Tahniyath M, Saksena S, Gill RK, Alrefai WA and Dudeja PK: LPA stimulates intestinal DRA gene transcription via LPA2 receptor, PI3K/AKT, and c-Fos-dependent pathway. Am J Physiol Gastrointest Liver Physiol 302: G618-G627, 2012

47. Brooks YS, Ostano P, Jo SH, Dai J, Getsios S, Dziunycz P, Hofbauer GF, Cerveny K, Chiorino G, Lefort K and Dotto GP: Multifactorial ER $\beta$ and NOTCH1 control of squamous differentiation and cancer. J Clin Invest 124: 2260-2276, 2014.

48. Kang L, Mao J, Tao Y, Song B, Ma W, Lu Y, Zhao L, Li J, Yang B and Li L: MicroRNA-34a suppresses the breast cancer stem cell-like characteristics by downregulating Notch1 pathway. Cancer Sci 106: 700-708, 2015.

49. Zang MD, Hu L, Fan ZY, Wang HX, Zhu ZL, Cao S, Wu XY, $\mathrm{Li} \mathrm{JF}, \mathrm{Su} \mathrm{LP}, \mathrm{Li} \mathrm{C}$, et al: Luteolin suppresses gastric cancer progression by reversing epithelial-mesenchymal transition via suppression of the Notch signaling pathway. J Transl Med 15: 52, 2017.

50. Liu T, Nie F, Yang X, Wang X, Yuan Y, Lv Z, Zhou L, Peng R, Ni D, Gu Y, et al: MicroRNA-590 is an EMT-suppressive microRNA involved in the TGF $\beta$ signaling pathway. Mol Med Rep 12: 7403-7411, 2015.

51. Shao S, Zhao X, Zhang X, Luo M, Zuo X, Huang S, Wang Y, $\mathrm{Gu} S$ and Zhao X: Notch1 signaling regulates the epithelialmesenchymal transition and invasion of breast cancer in a Slug-dependent manner. Mol Cancer 14: 28, 2015.

52. Hope JM, Wang FQ, Whyte JS, Ariztia EV, Abdalla W, Long K and Fishman DA: LPA receptor 2 mediates LPA-induced endometrial cancer invasion. Gynecol Oncol 112: 215-223, 2009.

53. Shida D, Kitayama J, Yamaguchi H, Hama K, Aoki J, Arai H, Yamashita H, Mori K, Sako A, Konishi T, et al: Dual mode regulation of migration by lysophosphatidic acid in human gastric cancer cells. Exp Cell Res 301: 168-178, 2004.

54. Suzuki HI, Horie M, Mihira $\mathrm{H}$ and Saito A: Molecular analysis of endothelial-mesenchymal transition induced by transforming growth factor- $\beta$ signaling. J Vis Exp, 2018.

55. Yang M, Zhong WW, Srivastava N, Slavin A, Yang J, Hoey T and An S: G protein-coupled lysophosphatidic acid receptors stimulate proliferation of colon cancer cells through the $\{$ beta\}-catenin pathway. Proc Natl Acad Sci USA 102: 6027-6032, 2005.

56. Yu S, Murph MM, Lu Y, Liu S, Hall HS, Liu J, Stephens C, Fang X and Mills GB: Lysophosphatidic acid receptors determine tumorigenicity and aggressiveness of ovarian cancer cells. J Nat Cancer Inst 100: 1630-1642, 2008.

57. Sun Y, Zhang R, Zhou S and Ji Y: Overexpression of Notch1 is associated with the progression of cervical cancer. Oncol Lett 9: 2750-2756, 2015.

58. Lin FT and Lai YJ: Regulation of the LPA2 receptor signaling through the carboxyl-terminal tail-mediated protein-protein interactions. Biochim Biophys Acta 1781: 558-562, 2008.

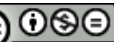

This work is licensed under a Creative Commons Attribution-NonCommercial-NoDerivatives 4.0 International (CC BY-NC-ND 4.0) License. 